\title{
IMMUNOHISTOCHEMICAL VALIDATION OF INSULIN-LIKE GROWTH FACTOR II mRNA-BINDING PROTEIN 3 (IMP3) AS A DIAGNOSTIC MARKER IN SALIVARY GLAND TUMORS
}

\author{
Nourhan A. Abou Madawi ${ }^{1^{*}} B D S$, Sahar M. El Sheikh² PhD, Sahar E. Riad² $P h D$, Gamal A. \\ Swaify ${ }^{3} P D$, Enas M. Omar ${ }^{4} P D$ \\ ABSTRACT
}

INTRODUCTION: Salivary gland tumors (SGTs) are infrequent tumours accounting for 2-6.5\% of all head and neck tumors. They show various clinical behaviours and different histological patterns resulting in a diagnostic dilemma. Insulin like growth factor II mRNA binding protein 3 (IMP3) is an oncofetal protein that plays an important role in tumor invasion and metastases. Several studies proved the prognostic role of IMP3 in different human cancers. However, its role in SGTs still needs to be confirmed.

OBJECTIVES: To evaluate IMP3 immunoexpression in benign and malignant SGTs.

MATERIALS AND METHODS: IMP3 expression was measured in 44 SGT cases (20 benign and 24 malignant) and 10 normal salivary gland tissues (NSGT). Immunohistochemical (IHC) staining was carried out by the Labeled Strept-Avidin Biotin complex method (LSAB). RESULTS: IMP3 expression was detected in NSGT as well as benign and malignant SGTs with different intensities. The Lowest expression levels were detected in NSGT, while the highest ones were detected in Malignant SGTs.

CONCLUSION: IMP3 could be used as a diagnostic marker in SGTs.

KEYWORDS: Salivary gland tumors, IMP3, immunohistochemical marker, prognosis.

1 Instructor in Oral Pathology Department, Faculty of Dentistry, Alexandria University.

2 Professor in Oral Pathology Department, Faculty of Dentistry, Alexandria University.

3 Professor in Cranio Maxillofacial and Plastic Surgery Department, Faculty of Dentistry, Alexandria University.

4 Lecturer in Oral Pathology Department, Faculty of Dentistry, Alexandria University.

* Corresponding author

Email: nourhanmadawi@gmail.com

\section{INTRODUCTION}

Salivary gland tumors (SGTs) are rare. They account for $2-6.5 \%$ of all head and neck tumors (1). SGTs mostly occur in adults and are less common in children of which a higher proportion are malignant (usually low-grade mucoepidermoid carcinomas). The most commonly affected site is the parotid gland (2). The majority of SGTs are benign. Pleomorphic adenoma is the most common tumour followed by Warthin's tumor (3). Benign salivary gland tumours (BSGTs) have better prognosis and lower rate of recurrence than malignant salivary gland tumors (MSGTs) (1).

The etiology of salivary gland cancer is not definite. While tobacco and alcohol consumption are important risk factors for most head and neck cancers, this is not the same in salivary gland cancer. However, radiation therapy involving the head and neck region may be a risk factor. A diet rich in vitamin $\mathrm{C}$ and low in cholesterol may be of value in preventing salivary gland cancer (4).
SGTs show variations in their clinical and histological appearance which make their diagnosis difficult (2). Immunohistochemical staining improves the accuracy of diagnosis. This procedure utilizes a biomarker which helps identify the biologic behavior of the tumor and its prognosis. It can also decide the proper way of treatment (5).

Insulin-like growth factor II mRNA-binding protein 3(IMP3) belongs to IMP family that consists of IMP1, IMP2, and IMP3. IMP family members have a significant role in RNA trafficking and stabilization, cell growth as well as cell migration during the early stages of embryogenesis (6). IMP3 is a protein encoded by gene IGF2BP3 which is located on chromosome 7p11.2 (7). It is also called $\mathrm{K}$ homology domain-containing protein overexpressed in cancer (KOC) or L523S (8). IMP3 is expressed in developing epithelium, muscle, and placenta during the early stages of human and mouse embryogenesis (9). IMP3 is also expressed in gonads, germinal centers of lymphoid follicles, hair follicles, and intestinal mucosa but at variable levels (10). IMP3 is 
epigenetically silenced soon after birth, with little or no detectable protein in normal adult tissues (9).

During embryogenesis, IMP3 is a prerequisite for the migration of cells that form the roof plate of the neural tube and, thereafter, for neural crest migration. From this point, it is proposed that IMP3 may be of value in enhancing cell migration. Furthermore, it has been found that IMP3 promotes tumor cell proliferation, adhesion, invasion, and metastasis (7).

IMP3 expression has been detected in diverse malignant tumors and its immense expression has been correlated with poor prognosis and developing metastases (11). IMP3 expression has been reported in various malignant neoplasms including oral cancer (8), prostate cancer(12), thyroid cancer(13), lung cancer $(14,15)$, esophageal cancer(16), colorectal cancer (17), bile duct cancer(18), cervical cancer(19), ovarian cancer(20), renal cancer(21), and bladder cancer(22).

To the best of our knowledge, only 2 studies concerning IMP3 expression in SGTs were found in the English literature $(23,24)$. The role of IMP3 in SGTs still needs to be confirmed.

The aim of the present work was to compare between IMP3 expression in BSGTs and MSGTs.

\section{MATERIALS AND METHODS}

The current study was carried out in the Faculty of Dentistry, Alexandria University after gaining the approval of the Research Ethics Committee. It included forty-four SGT cases (20 cases of BSGTs and 24 cases of MSGTs). Most cases were collected from the archives of the Oral Pathology Department from the period of 2015 to 2018. Few fresh tissue specimens were collected from the Cranio-Maxillofacial and Plastic Surgery Department. 10 sound salivary glands were taken from patients with oral squamous cell carcinoma (SCC) undergoing radical neck dissection at the Cranio-Maxillofacial and Plastic Surgery Department. Those served as negative control. Informed consents were taken from the patients to participate in the study.

The specimens were fixed in $10 \%$ neutral buffered formalin, processed and embedded in paraffin wax using the conventional procedures. Serial sections of 3-4 $\mu \mathrm{m}$ thickness were placed on glass slides and stained using Hematoxylin and Eosin (H\&E). Histopathological diagnosis of the cases was confirmed in the Oral Pathology Department at the Faculty of Dentistry, Alexandria University. Immunohistochemical (IHC) staining using IMP3 rabbit monoclonal antibody (Biocare Medical, USA, Catalog number 94553) was performed using the Labeled Strept- Avidin Biotin complex method (LSAB) (25). The sections were then examined, and the intensity of the immunostaining was calculated in terms of mean area percent (MA\%) and mean optical density (MOD) by the computer image analyser: ImageJ software (NIH, USA).

\section{Statistical analysis}

The data were analyzed using IBM SPSS software package version 20.0. (Armonk, NY: IBM Corp). The Kolmogorov-Smirnov test was used to test the normality of distribution. Quantitative data were described using range (minimum and maximum), mean, standard deviation and median. Qualitative data were described using number and percentage. A $\mathrm{p}$ value $<0.05$ was considered statistically significant. The values were recorded as a mean value \pm SD. F-test (ANOVA) was used for comparison between normal salivary gland tissue (NSGT), BSGTs and MSGTs according to MA\% and MOD of IMP3 expression. Pearson correlation coefficient was used for correlation between age with MA\% and MOD. Student t-test was used for relation between sex with MA\% and MOD. And finally, F-test (ANOVA) was used for relation between site with MA\% and MOD.

\section{RESULTS}

\section{Clinical results}

The demographic data of the patients included in the current study revealed that: The age of the patients ranged between 12 and 73 years. The mean age was found to be 44.34 years, while the median age was 43.5 years. Twenty-three patients $\mathbf{( 5 2 . 3 \% )}$ were females and twenty-one $\mathbf{( 4 7 . 7 \% )}$ ) were males. There were no significant differences regarding age and sex between BSGTs and MSGTs (Table 1). The most common site for both BSGTs and

\begin{tabular}{|c|c|c|c|c|c|c|}
\hline & \multicolumn{2}{|c|}{$\begin{array}{l}\text { Benign } \\
(\mathrm{n}=20)\end{array}$} & \multicolumn{2}{|c|}{$\begin{array}{l}\text { Malignant } \\
(\mathrm{n}=24)\end{array}$} & \multirow{2}{*}{$\begin{array}{l}\text { Test of } \\
\text { sig. }\end{array}$} & \multirow[t]{2}{*}{ p } \\
\hline & No. & $\%$ & No. & $\%$ & & \\
\hline $\begin{array}{l}\text { Sex } \\
\text { Male } \\
\text { Female } \\
\end{array}$ & $\begin{array}{l}9 \\
11 \\
\end{array}$ & $\begin{array}{l}45.0 \\
55.0 \\
\end{array}$ & $\begin{array}{l}12 \\
12 \\
\end{array}$ & $\begin{array}{l}50.0 \\
50.0\end{array}$ & $\begin{array}{l}\chi^{2}= \\
0.109\end{array}$ & $\begin{array}{l}0.7 \\
41 \\
\end{array}$ \\
\hline $\begin{array}{l}\text { Age } \\
\text { Min. - } \\
\text { Max. } \\
\text { Mean } \pm \\
\text { SD. } \\
\text { Median }\end{array}$ & 37.0 & $=18.71$ & \multicolumn{2}{|c|}{$\begin{array}{l}23.0-72.0 \\
48.50 \pm 14.27 \\
44.50\end{array}$} & $\begin{array}{l}U= \\
165.5\end{array}$ & $\begin{array}{l}0.0 \\
79\end{array}$ \\
\hline
\end{tabular}

MSGTs was the palate followed by the parotid gland.

Table (1): Comparison between Benign and Malignant Salivary Gland Tumours According to the Demographic data.

$\chi^{2}$ : Chi square test $\quad \mathrm{U}$ : Mann Whitney test

\section{Histopathological results}

Out of the 20 BSGTs, 8 were pleomorphic adenoma (PA), Warthin's tumor (WT) and myoepithelioma (ME) were represented by 4 cases each, while basal cell adenoma (BCA) and oncocytoma were represented by 2 cases each. Among the 24 MSGTs, 6 were mucoepidermoid carcinoma (MEC), adenoid cystic carcinoma (AdCC) and carcinoma ex pleomorphic adenoma (Ca ex $\mathrm{PA}$ ) were represented by 4 cases each. All of acinic cell carcinoma (ACC), salivary duct carcinoma (SDC), myoepithelial carcinoma (MC), basal cell adenocarcinoma (BCAC), and oncocytic carcinoma were represented by 2 cases each.

\section{Immunohistochemical results}


IMP3 immunoexpression was detected in NSGT, BSGTs and MSGTs. The expression was measured in terms of MA\% and MOD. The lowest values were found in NSGT, whereas the highest values were found in MSGTs. IMP3 immunoreactivity was predominantly cytoplasmic. Membranous reaction was detected in mucus secreting cells of low grade MEC, clear myoepithelial cells in Ca ex PA and MC, and clear cells in ACC. Membranous reaction was also detected in the ductal cells of $\mathrm{Ca}$ ex PA in addition to the cytoplasmic reaction. Nuclear IMP3 immunoreactivity was observed in some cells in BCAC besides the cytoplasmic staining (Figure 1, 2, 3, 4, 5and 6).

\section{Statistical analysis}

F-test (ANOVA) revealed a statistically significant difference between NSGT, BSGTs and MSGTs $(\mathrm{p}<0.001)$ (Table 2 \& 3). Correlation between both the MA\% and MOD with age, sex, and site were not statistically significant.

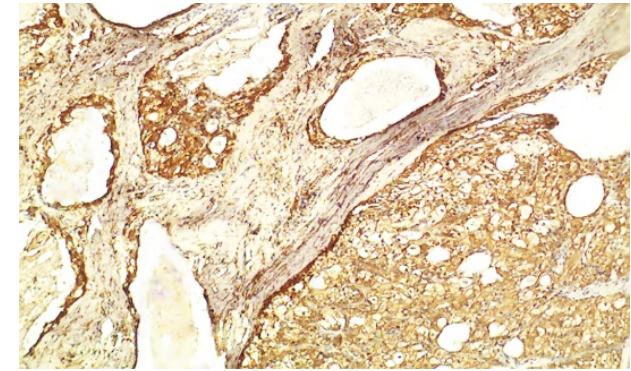

Figure 4: Low Grade Mucoepidermoid Carcinoma Showing Positive Membranous IMP3 Immunoreaction in the Mucus Secreting Cells (Blue arrow) and Cytoplasmic Expression in the Epidermoid Cells (Green arrow) (Immunostain of IMP3 x100).

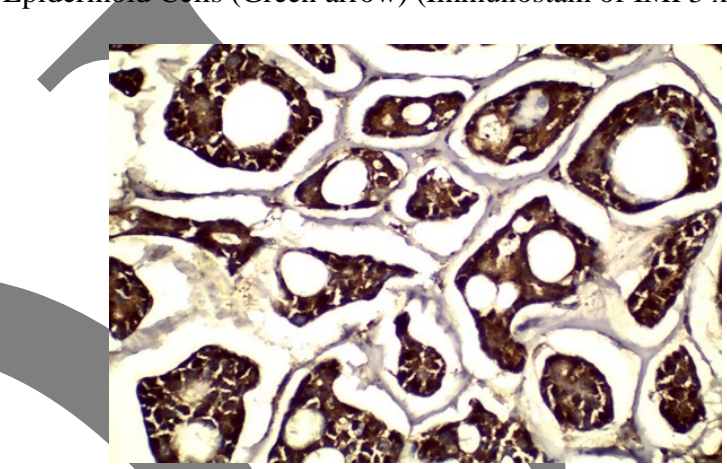

Figure 5: Adenoid Cystic Carcinoma Showing Strong Cytoplasmic IMP3 Immunostaining in the Basaloid Cells. The Hyalinized Stroma is Free From any Reaction (Immunostain of IMP3 x400).

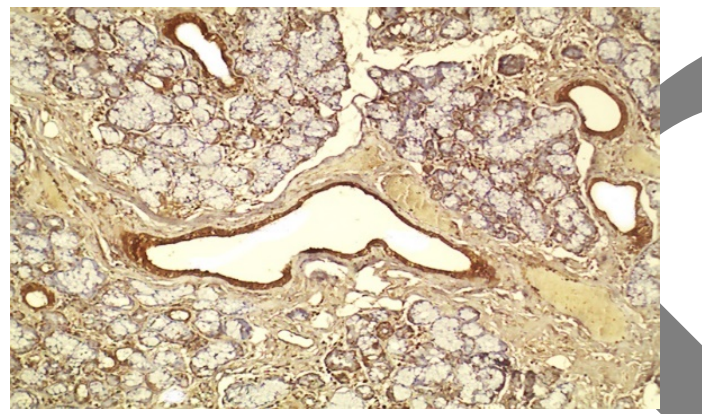

Figure 1: Normal Salivary Gland Tissue Showing Minimal IMP3 Immunostaining in the Ductal and Myoepithelial Cells (Immunostain of IMP3 x100).

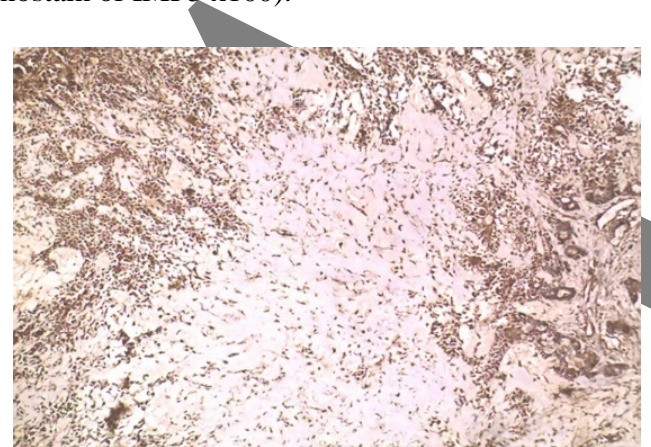

Figure 2: Pleomorphic Adenoma Revealing Positive Cytoplasmic IMP3 Expression. The Chondroid Stroma is Free From any Reaction (Immunostain of IMP3x100).

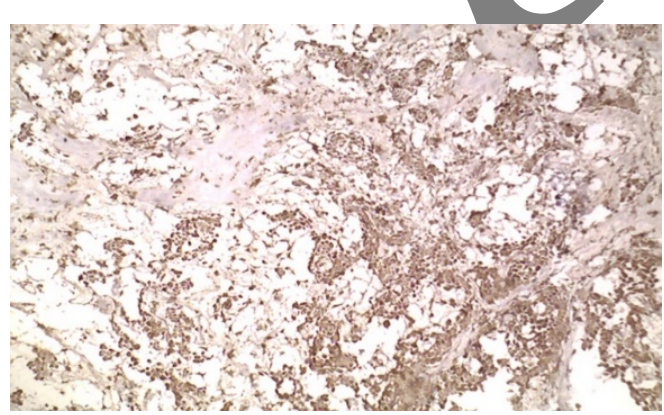

Figure 3: Myoepithelioma Showing Positive IMP3 Expression in the Myoepithelial Cells (Immunostain of IMP3 x100).
Table (2): Comparison between Normal Salivary Gland Tissue, Benign, and Malignant Salivary Gland Tumours According to Mean Area Percent of IMP3 Immunoexpression.

\begin{tabular}{|l|l|l|l|}
\hline \multicolumn{1}{|c|}{} & $\begin{array}{l}\text { NSGT } \\
(\mathrm{n}=10)\end{array}$ & $\begin{array}{l}\text { BSGTs } \\
(\mathrm{n}=20)\end{array}$ & $\begin{array}{l}\text { MSGTs } \\
(\mathrm{n}=24)\end{array}$ \\
\hline Min. - & $1.56-$ & $11.89-$ & $31.81-$ \\
Max. & 10.07 & 29.44 & 60.11 \\
Mean \pm & $6.31 \pm$ & $19.21 \pm$ & $42.43 \pm$ \\
SD. & 3.21 & 5.22 & 7.88 \\
Median & 7.44 & 17.91 & 42.03 \\
\hline Sig. bet. grps & \multicolumn{3}{|c|}{$\mathrm{p}_{1}<0.001^{*}, \mathrm{p}_{2}<0.001^{*}, \mathrm{p}_{3}<0.001^{*}$} \\
\hline
\end{tabular}

Figure 6: Basal Cell Adenocarcinoma Showing Positive IMP3 Immunostaining in the Basaloid Cells. Palisading of the Peripheral Cells is Noted (Green arrow) (Immunostain of IMP3 $\mathrm{x} 400)$.

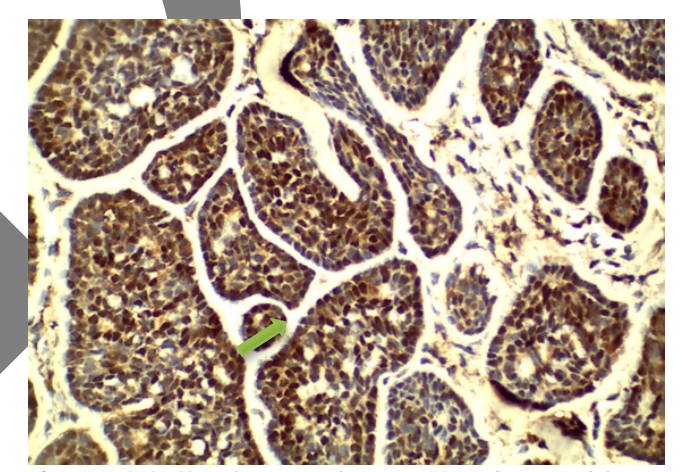


F: F for ANOVA test, Pairwise comparison bet. each 2 groups was done using Post Hoc Test (Tukey) p: p value for comparing between the three studied groups $\mathrm{p}_{1}$ : $\mathrm{p}$ value for comparing between Benign and Malignant $\mathrm{p}_{2}$ : $\mathrm{p}$ value for comparing between Benign and Control $\mathrm{p}_{3}$ : $\mathrm{p}$ value for comparing between Malignant and

\section{Control}

*: Statistically significant at $\mathrm{p} \leq 0.05$

Table (3): Comparison between Normal Salivary Gland Tissue, Benign, and Malignant Salivary Gland Tumours According to Mean Optical Density of IMP3 Immunoexpression.

\begin{tabular}{|c|c|c|c|c|c|}
\hline & $\begin{array}{l}\text { NSG } \\
\mathrm{T} \\
(\mathrm{n}= \\
10)\end{array}$ & $\begin{array}{l}\text { BSGT } \\
\text { s } \\
(n= \\
20)\end{array}$ & $\begin{array}{l}\text { MSGT } \\
\text { s } \\
(n= \\
24)\end{array}$ & $\mathrm{F}$ & $\mathrm{p}$ \\
\hline Min. - & $\begin{array}{l}12.74 \\
-\end{array}$ & $\begin{array}{l}20.28 \\
-\end{array}$ & $\begin{array}{l}33.21 \\
-\end{array}$ & & \\
\hline IVIdX. & 18.44 & 37.44 & 78.56 & & \\
\hline $\begin{array}{l}\text { Mean } \\
\pm \text { SD }\end{array}$ & $\begin{array}{l}15.91 \\
\pm \\
1.56\end{array}$ & $\begin{array}{l}29.87 \\
\pm 4.67\end{array}$ & $\begin{array}{l}50.80 \\
\pm \\
11.50\end{array}$ & & \\
\hline $\begin{array}{l}\text { Media } \\
\mathrm{n}\end{array}$ & 1.56 & 30.01 & 48.48 & & \\
\hline $\begin{array}{l}\text { Sig. } \\
\text { bet. } \\
\text { grps }\end{array}$ & \multicolumn{3}{|c|}{$\begin{array}{l}\mathrm{p} 1<0.001^{*}, \mathrm{p} 2<0.001^{*}, \\
\mathrm{p} 3<0.001^{*}\end{array}$} & & \\
\hline
\end{tabular}

F: F for ANOVA test, Pairwise comparison bet. each 2 groups was done using Post Hoc Test (Tukey) $\mathrm{p}$ : $\mathrm{p}$ value for comparing between the three studied groups $\mathrm{p}_{1}$ : $\mathrm{p}$ value for comparing between BSGTs and MSGTs $\mathrm{p}_{2}$ : $\mathrm{p}$ value for comparing between BSGTs and NSGT $\mathrm{p}_{3}$ : $\mathrm{p}$ value for comparing between MSGTs and NSGT *: Statistically significant at $\mathrm{p} \leq 0.05$

DISCUSSION

SGTs are the most heterogenous tumors in the human body. They are characterized by their complex biological behaviour and variable morphology. In spite of their heterogeneity, they are infrequent with an annual incidence of 0.4 to 13.5 per 100,000 individuals worldwide (26). The diagnosis of SGTs is challenging owing to their histologic diversity. Furthermore, it is substantial to decide whether the tumor is benign or malignant because it affects the line of treatment and follow up (1). IMP3 is a member of IMP family that are vastly expressed in human tissues during embryogenesis, yet they disappear in adult tissues. IMP3 expression in adult tissues has been linked to cancer (27). IMP3 enhances tumor progression, invasion, and metastases and its expression has been linked to poor prognosis in a wide range of human cancers. However, it is absent or minimally expressed in benign tumors. Subsequently, IMP3 is considered as an important prognostic biomarker (7). In the present study, IMP3 expression was measured in NSGT, BSGTs and MSGTs aiming at evaluating the role of IMP3 in the progression of salivary gland pathology.

The present work showed that the palate was the most commonly affected site for both BSGTs and MSGTs. This is in contrast to the results of many studies in the literature which reported that the parotid gland was the predominant site of SGTs $(26,28,29)$. Our result is in concordance with Phattarataratip et al (30) who also found that the palate was the prevalent site.

In the current study, the most common histopathological type of all SGTs was PA. This is consistent with several studies reported in the literature $(31,32)$. On the other hand, the most common MSGT was MEC. Similar finding was observed by different authors $(29,32)$. However, Sando et al (33) and Hussain et al (34) found that AdCC was the most common MSGT in their studies.

Regarding IMP3 expression, it was detected in NSGT at very low level particularly in the ductal cells and myoepithelial cells. Similar results were found in the study of Ismerim et al (23) who observed IMP3 expression in normal salivary ductal cells. Conversely, ElShafey et al (24) didn't find IMP3 expression in NSGT.

Several authors reported negative IMP3 expression in normal tissues other than salivary glands. In the work of Feng et al (16), IMP3 expression was absent in normal esophageal mucosa. Likewise, Chen et al (18) detected negative IMP3 expression in normal hepatic tissue. IMP3 expression was not detected in normal prostate tissue in the study of Ikenberg et al (12). Also, IMP3 expression was absent in normal colorectal epithelium in the study of Lochhead et al (17).

In the present study, IMP3 expression was higher in MSGTs than in BSGTs with a statistically significant difference in between supporting its role in tumor aggressiveness (7). This is in agreement with the study of ElShafey et al (24) who detected significant difference between PA and MEC.

Similar results were found in studies conducted on other tumors. Wei et al (35) detected high IMP3 expression in colorectal carcinomas and low expression in colorectal adenomas. Moreover, Senoo et al (36) found that IMP3 expression was higher in malignant intraductal papillary mucinous neoplasms than in their benign counterparts. Also, Kanzaki et al (37) reported positive IMP3 expression in cutaneous SCC, whereas there was no IMP3 expression in keratoacanthoma.

In contrast with our results, Ismerim et al (23) found no significant difference in IMP3 expression between their studied SGTs. This may be explained by the few types of tumors involved in their study and not including high grade tumors. Similarly, Kulaçoğlu and Erkılınç (13) found no significant difference in IMP3 expression between benign and malignant thyroid tumors. This may be attributed to variations in technical work or the clones of the antibodies used in different studies. Conversely, Slosar et al (38) detected negative IMP3 expression in follicular adenoma of the thyroid gland and positive 
expression in follicular variant of papillary thyroid carcinoma.

In the current study, the expression of IMP3 was predominantly in the cytoplasm. This is in accordance with numerous studies in which cytoplasmic immunostaining was observed $(7,8,16,35)$. This is interpreted that IMP3 protein is present in the cytoplasm (39). Besides, membranous reaction was detected in certain MSGTs such as MEC, Ca ex PA, ACC and MC. Membranous reaction was also observed in esophageal adenocarcinoma in the study of Feng et al (16).

Nuclear reaction was detected in some cell nuclei in basal cell adenocarcinoma. This is in agreement with Ismerim et al (23), where IMP3 was positively expressed in the cell nuclei of PA and AdCC. This may be explained by mRNA regulation following transcription, some of whose proteins are located in the nucleus.

In the present work, in WT, few lymphocytes in the lymphoid stroma were positive for IMP3 expression. Similar finding was detected in the study of Lochhead et al (17) on colorectal cancer, where germinal centre lymphocytes in the lymphoid tissue of normal colonic mucosa adjacent to neoplastic tissue were positive for IMP3. Correspondingly, positive IMP3 expression has been observed in B cells present in the germinal centers of normal lymphoid tissue such as tonsil, lymph node and spleen (40).

In the present work, there were no significant correlations between IMP3 expression with age, sex and site of the included cases. This goes with the results of many authors $(16,17,18)$. However they found significant correlation with the tumor stage.

It has been elucidated by several investigators that IMP3 is a valuable diagnostic tool and can differentiate between high grade preneoplastic lesions and neoplasms (6, 14, and 19). According to the study of Wei et al (19) on cervical SCC, IMP3 expression was absent in normal cervical tissue as well as low grades of cervical intraepithelial neoplasia. However, its positive immunoreactivity was detected in intraepithelial neoplasia grade III and SCC supporting its role in tumor progression. Regarding salivary gland tissue, there are no preneoplastic lesions, but rather benign and malignant tumors. In our study, IMP3 was strongly expressed in MSGTs as compared to its expression in BSGTs, thus IMP3 could be considered as a diagnostic marker of SGTs.

\section{CONCLUSIONS}

IMP3 immunoexpression was detected in NSGT, BSGTs and MSGTs. The expression was higher in MSGTs than in BSGTs, thus IMP3 could be used as a diagnostic marker of SGTs.

\section{CONFLICT OF INTEREST}

The authors declare that they have no conflicts of interest.

\section{REFERENCES}

1. Freling N, Crippa F, Maroldi R. Staging and follow-up of high-grade malignant salivary gland tumours: The role of traditional versus functional imaging approaches - A review. Oral Oncol.2016; 60:157-66.

2. Sood S, McGurk M, Vaz F. Managment of Salivary Gland Tumors: United Kingdom National Multidisciplinary Guidelines. J Laryngol Otol.2016; 130:S142-S9.

3. Lima SS, Soares AF, Batista de Amorim RF, Freitas RA. Epidemiologic profile of salivary gland neoplasms. Braz J Otorhinolaryngol.2005; 71:335-40.

4. To VSH, Chan JYW, Tsang RKY, Wei WI. Review of Salivary Gland Neoplasms. ISRN Otolaryngol.2012; 2012:1-6.

5. Namboodiripad PCA. A review: Immunological markers for malignant salivary gland tumors. JOBCR.2014; 4:127-34.

6. Del Gobbo A, Vaira V, Ferrari L, Patriarca C, Di Cristofori A, Ricca D, et al. The Oncofetal Protein IMP3: A Novel Grading Tool and Predictor of Poor Clincal Outcome in Human Gliomas.BMRI.2015; 2015:1-10.

7. Gong Y, Woda B, Jiang Z. Oncofetal Protein IMP3, a new cancer biomarker. Adv Anat Pathol.2014; 21:191200.

8. Lin C-Y, Chen S-T, Jeng Y-M, Yeh C-C, Chou H-Y, Deng Y-T, et al. Insulin-like growth factor II mRNAbinding protein 3 expression promotes tumor formation and invasion and predicts poor prognosis in oral squamous cell carcinoma. J Oral Pathol Med.2011; 40:699-705.

9. Mueller-Pillasch F, Pohl B, Wilda M, Lacher U, Beil M, Wallrapp C, et al. Expression of the highly conserved RNA binding protein KOC in embryogenesis. Mech Dev.

10. Xu H. IMP3: a diagnostic and prognostic biomarker in malignant melanoma. Expert Rev Mol Diagn.2008; 8:557-8.

11.Jennifer J, Findeis-Hosey, Haodong $X$. The use of insulin-like growth factor II messenger RNA binding protein-3 in diagnostic pathology. Hum Pathol.2011; 42:303-14.

12.Ikenberg K, Fritzsche FR, Zuerrer-Haerdi U, Hofmann I, Hermanns T, Seifert $\mathrm{H}$, et al. Insulin-like growth factor II mRNA binding protein 3 (IMP3) is overexpressed in prostate cancer and correlates with higher Gleason scores. BMC Cancer.2010; 10:341.

13. Kulacoglu S, Erkilinc G. IMP3 Expression in Benign and Malignant Thyroid Tumors and Hyperplastic Nodules. Balcan Med J.2015; 32:30-7.

14. Findeis-Hosey JJ, Xu H. Insulin-like growth factor IImessenger RNA-binding protein-3 and lung cancer. Biotech Histochem.2011; 87:24-9.

15. Yan J, Wei Q, Jian W, Qiu B, Wen J, Liu J, et al. IMP3 Predicts Invasion and Prognosis in Human Lung Adenocarcinoma.Lung.2016;194:137-46.

16. Feng W, Zhou Z, Peters JH, Khoury T, Zhai Q, Q.W, et al. Expression of Insulin like growth factor II mRNA binding protein 3 in esophageal adenocarcinoma and its 
precursor lesions. Arch Pathol Lab Med.2011; 135:1024-

17. Lochhead $\mathrm{P}$, Imamura $\mathrm{Y}$, Morikawa $\mathrm{T}$, Kuchiba $\mathrm{A}$, Yamauchi M, Liao Y, et al. Insulin-like growth factor 2 messenger RNA binding protein 3 (IGF2BP3) is a marker of unfavourable prognosis in colorectal cancer. Eur J Cancer.2012; 48:3405-13.

18. Chen Y-L, Jeng Y-M, Hsu H-C, Lai H-S, Lee P-H, Lai P-L, et al. Expression of insulin-like growth factor II mRNA-binding protein 3 predicts early recurrence and poor prognosis in intrahepatic cholangiocarcinoma. Int $\mathrm{J}$ Surg. 2013; 11:85-91.

19. Wei Q, Yan J, Fu B, Liu J, Zhong L, Yang Q, et al. IMP3 expression is associated with poor survival in cervical squamous cell carcinoma. Hum Pathol.2014; 45:2218-24.

20.Hsu KF, Shen MR, Huang YF, Cheng YM, Lin SH, Chow $\mathrm{NH}$, et al. Overexpression of the RNA-binding proteins Lin 28B and IGF2BP3 (IMP3) is associated with chemoresistance and poor disease outcome in ovarian cancer. Br J Cancer.2015; 113:414-24.

21.Xie C, Li Y, Li Q, Chen Y, Yao J, Yin G, et al. Increased insulin mRNA binding protein-3 expression correlates with vascular enhancement of renal cell carcinoma by intravenous contrast-CT and is associated with bone metastases. J Bone Oncol.2015; 4:69-76.

22. Zhao B, ZhaoY, Jiang HP, Cao YW, Wang YH, Yang $\mathrm{XC}$, et al. The role of insulin-like growth factor axis in bladder cancer: a systemic review and meta analysis. Int J Clin Exp Med. 2016; 9:784-93.

23. Ismerim AB, Ferreira SV, Lessa AM, Pereira Ju'nior AS, Gurgel CA, Coutinho-Camillo CM, et al. Insulinlike Growth Factor II Messsenger RNA-binding Protein 3 in Salivary Gland Tumors. Appl Immunohistochem Mol Morphol.2016; 24:422-6.

24. ElShafey MR, Ahmed RA, Mourad MI, Gaballah ET. The oncofetal protein is an indicator of early recurrence and poor outcome in mucoepidermoid carcinoma of salivary glands. Cancer Biol Med. 2016;13:286-95.

25. Syrbu SL, Cohen MB. An enhanced Antigen-Retrieval Protocol for Immunohistochemical Staining of Formalin-Fixed, Paraffin-Embedded Tissues. Methods Mol Biol.2011; 717:101-10.

26. da Silva LP, Serpa MS, Viveiros SK, Sena DAC, de Carvalho Pinho RF, de Abreu Guimaraes LD, et al. Salivary gland tumors in a Brazilian population: A 20year retrospective and multicentric study of 2292 cases. J Craniomaxillofac Surg.2018; 46:2227-33.

27. Degrauwe N, Suva ML, Janiszewska M, Riggi N, Stamenkovic I. IMPs: an RNA-binding protein family that provides a link between stem cell maintenance in normal development and cancer. Genes Dev.2016; 30:2459-74.
28. Afroza K, Gulshan A, Rahman MA. Pattern of distribution of different salivary gland tumor;a retrospective study in NICRH, Dhaka. Bangladesh J Med Sci. 2016; 15:95-8.

29. Aquino G, Collina F, Sabatino R, Cerrone M, Longo F, Ionna F, et al. Sex Hormone Receptors in Benign and Malignant Salivary Gland Tumors: Prognostic and Predictive Role. Int J Mol Sci. 2018; 19:399.

30. Phattarataratip E, Kositkittiwanit N, Kajornkiatkul P, Yeunyong P, Ratanapitak R. P120 catenin expression and its correlation with E-cadherin in salivary gland neoplasms. J Oral Biol Craniofac Res. 2019; 9:57-62.

31. Khattak MS, Ahmad S, Noman N. The histological pattern of salivary gland tumors. Gomal J Med Sci. 2016; 14:203-7.

32. Sharma S, Bargotra R, Kaul KK. Morphological patterns of salivary gland tumors. JK Science. 2017; 19:48-52.

33. Sando Z, Fogha JV, Mebada AO, Djomou F, Ndjolo A, Essame JL. Epidemiological and histopathological patterns of salivary gland tumors in Cameroon. Pan Afr Med J. 2016; 23.

34.Hussain S, Nassem N, Nagi AH. Age, gender and site distribution of salivary gland tumors reported at tertiary care hospitals. Biomedica. 2016; 32.

35. Wei Q, Zhou H, Zhong L, Shi L, Liu J, Yang Q, et al. IMP3 expression in biopsy specimens as a diagnostic biomarker for colorectal cancer. Hum Pathol.2017; 64:137-44.

36. Senoo J, Mikata R, Kishimoto T, Hayashi M, Kusakabe $\mathrm{Y}$, Yasui S, et al. Immunohistochemical analysis of IMP3 and p53 expression in endoscopic ultrasoundguided fine needle aspiration and resected specimens of pancreatic diseases. Pancreatology. 2018; 18:176-83.

37. Kanzaki A, Kudo M, Ansai S-I, Peng W-X, Ishino K, Yamamoto $\mathrm{T}$, et al. Insulin like growth factor II mRNA binding protein as a marker for distinguishing between cutaneous squamous cell carcinoma and keratoacanthoma. Int J Oncol.2016;48:1007-15

38. Slosar M, Vohra P, Prasad M, Fischer A, Quinlan R, Khan A. IMP3 is differentially expressed in benign and malignant follicular patterned thyroid tumors. Endocr Pathol.2009; 20:149-57.

39. Bell JL, Wachter K, Muhleck B, Pazaitis N, Kohn M, Lederer $\mathrm{M}$, et al. Insulin-like growth factor 2 mRNAbinding proteins (IGF2BPs): Post-transcriptional drivers of cancer progression? Cell Mol Life Sci. 2013; 70:2657-75.

40. King RL, Pasha T, Roullet MR, Zhang PJ, Bagg A. IMP-3 is differentially expressed in normal and neoplastic lymphoid. Hum Pathol.2009; 40:1699-705. 